\title{
PENETRATION INTO DRY POROUS ROCK: A NUMERICAL STUDY ON SLIDING FRICTION SIMULATION
}

\author{
E. P. Chen \\ Applied Mechanics Division III \\ Sandia National Laboratories \\ Albuquerque, New Mexico 87185
}

\begin{abstract}
Penetration of Antelope tuff targets by steel penetrators is the subject of discussion in the present investigation. Specifically, the effect of sliding friction between projectile and target on penetration is examined. The finite element code PRONTO 2D is used to perform a parametric study of the coefficient of friction. Both constant and velocity dependent coefficient of friction representation have been included in the current investigation. Results indicate that increases in the coefficient of friction increase the penetration resistance although the relationship is nonlinear in nature. In terms of peak deceleration and depth of penetration, both the constant and velocity dependent coefficient of friction representation provide almost identical results. However, only the velocity dependent cases show the characteristic of increasing deceleration prior to the conclusion of the penetration event. For this reason, the velocity dependent representation of the coefficient of friction is preferred over the constant friction coefficient representation.
\end{abstract}

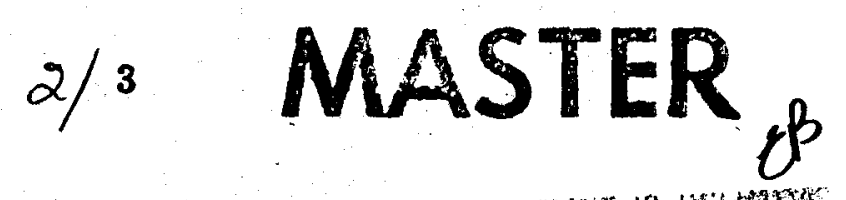




\section{DISCLAIMER}

This report was prepared as an account of work sponsored by an agency of the United States Government. Neither the United States Government nor any agency Thereof, nor any of their employees, makes any warranty, express or implied, or assumes any legal liability or responsibility for the accuracy, completeness, or usefulness of any information, apparatus, product, or process disclosed, or represents that its use would not infringe privately owned rights. Reference herein to any specific commercial product, process, or service by trade name, trademark, manufacturer, or otherwise does not necessarily constitute or imply its endorsement, recommendation, or favoring by the United States Government or any agency thereof. The views and opinions of authors expressed herein do not necessarily state or reflect those of the United States Government or any agency thereof. 


\section{DISCLAIMER}

Portions of this document may be illegible in electronic image products. Images are produced from the best available original document. 


$$
A^{2}+r
$$




\section{Contents}

Figures . . . . . . . . . . . . . . . . 5

Tables . . . . . ... . . . . . . . . . . 6

1 Introduction . . . . . . . . . . . . . . . . . . . 7

2 Problem Description . . . . . . . . . . . . . . . . . . 9

3 Finite Element Computational Procedure . . . . . . . . . . . 13

4 Results and Discussions . . . . . . . . . . . . . . . . . 15

5 Summary . . . . . . . . . . . . . . . . . 27

References . . . . . . . . . . . . . . . . . 28

Figures

1 Penetrator Geometry . . . . . . . . . . . . . . 9

2 Finite Element Mesh _ . . . . . . . . . . . . 12

3 Velocity Dependent Friction Coefficients . . . . . . . . . . 14

4 Experimental Data on Deceleration History . . . . . . . . 15

5 Early Time Deformed Mesh Plots . . . . . . . . . . . . 18

6 Late Time Deformed Mesh Plots . . . . . . . . . . 19

7 Displacement History Plots for Constant $\mu$. . . . . . . 20

8 Velocity History Plots for Constant $\mu$. . . . . . . . 21

9 Deceleration History Plots for Constant $\mu$. . . . . . . 22

10 Displacement History Plots for Velocity Dependent $\mu$ _ . . . 23

11 Velocity History Plots for Velocity Dependent $\mu$. . . . . 24

12 Deceleration History Plots for Velocity Dependent $\mu$. _ . . 25

13 Decelerations for $\mu$ and $\mu_{\infty}$ Equal to $0.05 \ldots \ldots \ldots$

$$
4 / 5
$$




\section{Tables}

1 Steel Mechanical Properties . . . . . . . . . . . . . . 10 


\section{Introduction}

In many problems involving penetration into geological targets, it is important to determine the forces imparted to the penetrator by the target material during the penetration process. One of the mechanisms which has been recognized to contribute to the increase in resistance to penetration is the sliding friction between the penetrator and target material. However, this is also one of the least understood areas in penetration analysis. In most cases, a simple Coulomb friction formula in the form of $f=\mu \mathrm{N}$ has been assumed, where $\mathrm{f}$ and $\mathrm{N}$ are, respectively, the forces tangent and normal to the interface and $\mu$ is the coefficient of friction. In the Coulomb friction formula, the coefficient of friction $\mu$ can be taken either as a constant or as a function of the penetration velocity. Longcope and Forrestal [1] and Forrestal [2] have studied the effect of sliding friction in geological target penetration problems in the context of the cavity expansion method. To the author's best knowledge, no similar analysis on sliding friction based on the finite element method exists in the literature.

In this investigation, a parametric study on the effect of sliding friction in penetrating geological targets is conducted using the finite element code PRONTO 2D [3]. In general, the friction mechanism in finite element codes is modeled by the contact surface algorithms. The contact surface algorithm in PRONTO 2D models Coulomb friction with either a constant coefficient of friction or a velocity dependent friction law expressed by

$$
\mu=\mu_{\infty}+\left(\mu_{0}-\mu_{\infty}\right) \mathrm{e}^{-\gamma v_{0}}
$$

where $\mu_{0}$ and $\mu_{\infty}$ are the low and high velocity friction coefficients, respectively, $\gamma$ is a decay constant, and $v_{d}$ is the velocity. Note that as $v_{1} \rightarrow 0$, the friction coefficient $\mu$ takes the value of the low velocity coefficient $\mu_{0}$. Both the constant and the velocity dependent friction coefficient representation have been used in the present study to simulate the effect of sliding friction. Within each representation, a range of friction coefficient values have been included in the study. The physical problem selected for this study is the Antelope tuff penetration experiment conducted by Young [4]. The problem was chosen because it has been treated previously by Chen [5] using PRONTO 2D without considering the effect of sliding friction. In general, the results indicate that increasing friction coefficient increases the resistance to penetration. This increase in penetration resistance is not linearly proportional to the increase in the coefficient of friction. In terms of peak deceleration and depth of penetration, both the constant and the velocity dependent friction coefficient representations pro- 
vide almost identical results. However, because of the observed increase in the magnitude of the deceleration in the penetrator immediately preceding the conclusion of the penetration event, the velocity dependent friction coefficient representation is judged to simulate the effect of sliding friction better than the constant friction representation. 


\section{Problem Description}

In this section, descriptions of the test configuration and the finite element simulation of the antelope tuff field test [4] are presented. The test geometry consists of a steel penetrator (Figure 1) with a 6.0 CRH (caliber radius head) ogival nose, a total length of $1.56 \mathrm{~m}$, an aft-body diamater of $0.156 \mathrm{~m}$, and mass $162 \mathrm{~kg}$ which was propelled with a $0.305-\mathrm{m}$ - diameter, smooth-bore, recoilless gun (Davis gun) to an impact velocity of $520 \mathrm{~m} / \mathrm{s}$ into a semi-infinite antelope tuff medium. It is necessary in Davis gun tests to use a pusher plate fitted to the end of the penetrator in order

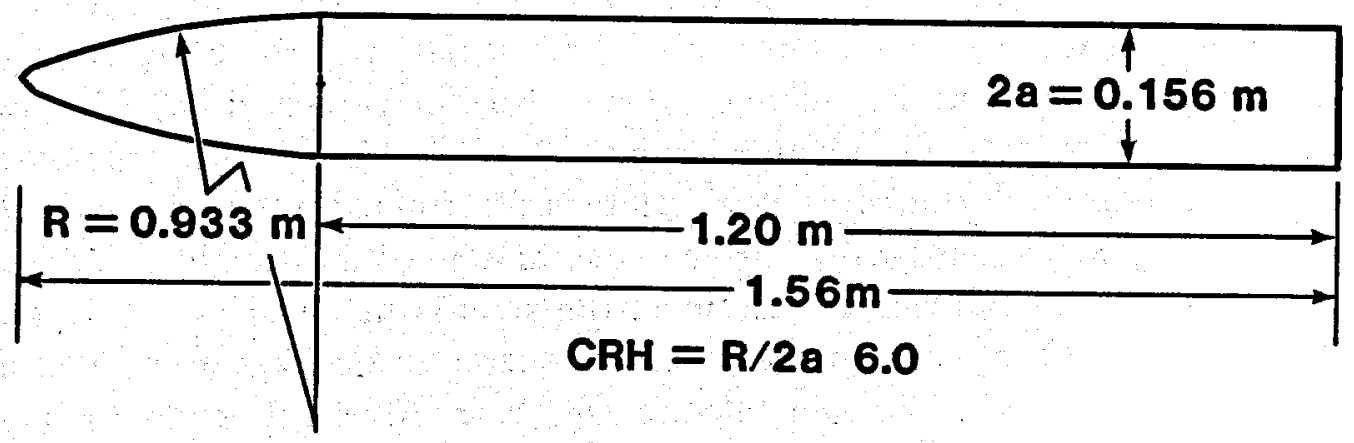

Figure 1. Penetrator Geometry

to fill the inside diameter of the bore and carry the gun pressure. In the Antelope tuff field test, a steel pusher plate weighing $55 \mathrm{~kg}$ was used.

In the finite element idealization in Figure 2, the ogival nose shape of the penetrator and the pusher plate have been included in the model. This is in contrast to the previous analysis in [5] where the ogival nose was approximated by a conical nose and the pusher plate was not modeled. The finite element mesh in Figure 2 consists of 3008 elements and $\mathbf{3 1 6 6}$ nodes. Because of axisymmetry, only half of the actual geometry needs to be included in the finite element model. Both the penetrator and the pusher plate are made of steel whose mechanical properties are given in Table 1. These are standard steel properties with the exception of the mass density value of $6.2 \mathrm{Mg} / \mathrm{m}^{3}$ which is low in comparison to the commonly used value of $7.8 \mathrm{Mg} / \mathrm{m}^{3}$. 
This is because in the test, materials were removed from the penetrator to accommodate instrumentation packages. Since in the finite element model, the penetrator is modeled as a solid material, the mass density of the steel is adjusted in order to recover the correct weight for the penetrator. The adjustment in mass density affects

Table 1. Steel Mechanical Properties

\begin{tabular}{|cc|}
\hline Mass Density & $6.2 \mathrm{Mg} / \mathrm{m}^{3}$ \\
Young's Modulus & $200.0 \mathrm{GPa}$ \\
Poisson's Ratio & 0.32 \\
Yield Stress & $0.896 \mathrm{GPa}$ \\
Hardening Modulus & $1.186 \mathrm{GPa}$ \\
\hline
\end{tabular}

the wave velocity which in turn, influences the high frequency response of the penetrator. It is not expected to influence significantly the rigid body response of the penetrator. Since the primary purpose of the calculation is to obtain the rigid body responses of the penetrator so as to compare with the measure data, this adjustment in mass density is justified. The pusher plate is taken to have the same diameter as the Davis gun and the thickness of the plate is determined by using the combination of the $6.2 \mathrm{Mg} / \mathrm{m}^{3}$ mass density for the steel and the total weight of $55 \mathrm{~kg}$ for the plate. In the finite element calculations, the steel is modeled as an elastic/plastic material with the properties in Table 1 with the additional assumption of isotropic hardening. Only six and two elements are used, respectively, to model the penetrator and the pusher plate because steel is stiffer than tuff such that little deformation is expected in the penetrator and the pusher plate. This has also been confirmed from post-test examinations.

By taking advantage of the nonreflecting surface capability in PRONTO 2D [3], the semi-infinite Antelope tuff target is modeled as a $9 \mathrm{~m}$ deep and $1 \mathrm{~m}$ in radius block. The right-hand side and bottom surfaces of the block are designated as nonreflecting surfaces. These surfaces essentially prevent the reflection of waves impinging on them. The use of these surfaces reduces the target size to manageable proportions for the finite element analysis. For the target material properties, Longcope and Forrestal [1] have shown that a linear hydrostat and a linear, Mohr-Coulomb failure criterion provide good approximations to triaxial test data for Antelope tuff. They described the inelastic material response by

$$
\begin{aligned}
& p=K\left(1-\rho_{0} / \rho\right)=K \eta \\
& \sigma_{r}-\sigma_{\theta}=s p+\tau_{0} ; \quad \tau_{0}=(1-s / 3) Q \\
& \sigma_{\theta} \geq-Y
\end{aligned}
$$


where $\mathrm{p}$ is the hydrostatic pressure, $\rho_{0}$ and $\rho$ are densities in the undeformed and deformed configurations, $\eta$ is volumetric strain, $\sigma_{\mathrm{r}}$ and $\sigma_{\theta}$ are radial and circumferential stress components, $s$ and $\tau_{0}$ define the failure criterion, $Q$ is the unconfined compressive strength, and $Y$ is the tensile strength. The soil and crushable foam model in PRONTO 2D [3] can describe the material responses given by the above equations exactly. From published data by Forrestal [2] and Hightower [6], numerical values of $\rho_{0}=1.71 \mathrm{Mg} / \mathrm{m}^{3}, K=2.0 \mathrm{GPa}, \mathrm{Q}=15.0 \mathrm{MPa}, \tau_{0}=10.0 \mathrm{MPa}, \mathrm{s}=1.0$, and $Y=1.72 \mathrm{MPa}$ are used in the present calculation for Antelope tuff. In addition, the shear modulus of the material is a required input to the soil and crushable foam model in PRONTO 2D. Using a Young's modulus value of $5 \mathrm{GPa}$, as suggested by [6], and a Poisson's ratio of $\mathbf{0 . 2 3 4}$, the shear modulus of the Antelope tuff is estimated to be $2.03 \mathrm{GPa}$. 


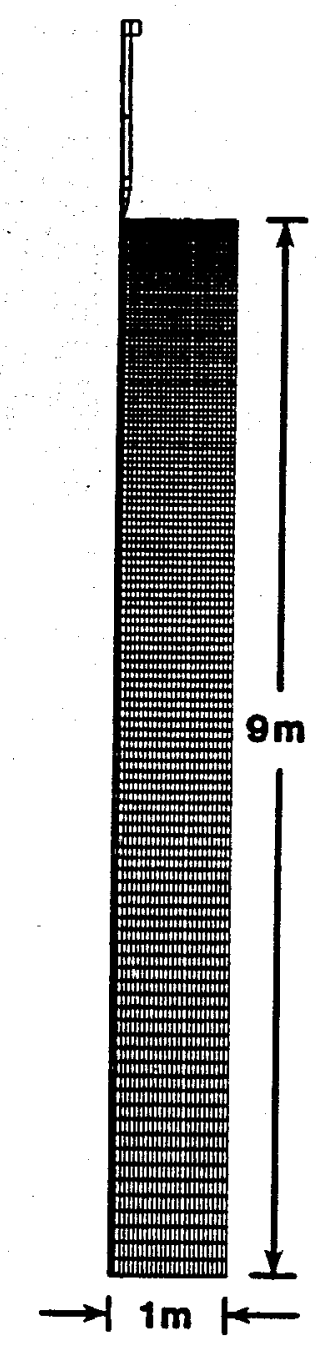

(a) FULL VIEW

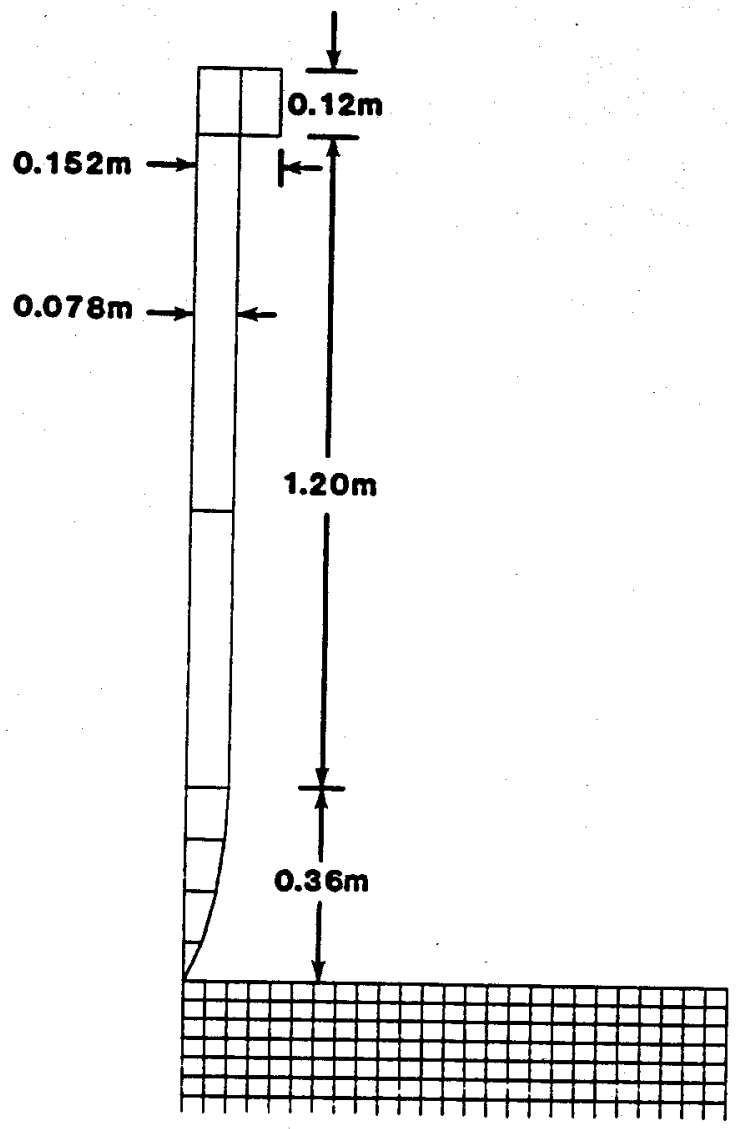

(b) ZOOMED VIEW OF PENETRATOR

Figure 2. Finite Element Mesh 


\section{Finite Element Computational Procedure}

The computational procedure is similar to that in [5] except for the treatment of the pusher plate and the ogive nose. Specifically, the pilot hole (or tunneling) assumption has been invoked. This amounts to displacing the nodes in the target that are located on the axis of symmetry by an infinitesimal amount from that axis, thus relieving the displacement constraints on these nodes. Physically, this is the same as creating a crack at the center of the target block and thus preassigning the path of penetration. This is required because the elastic/plastic model assumed for the target provides no fracture mechanism to allow material separation. As has been discussed in [5], for normal penetration problems, the pilot hole assumption under the penetrator nose seems reasonable since symmetry constrains the penetrator to advance along at the center of the target.

The penetrator and the pusher plate combination are moving downward initially into the target at $520 \mathrm{~m} / \mathrm{s}$. The end surface of the penetrator is assumed to be in frictionless contact with the front surface of the pusher plate. Posttest observations indicated that the pusher plate was stripped from the penetrator by the target material. In the current calculation, a rigid wall boundary condition at the top surface of the target is assumed for the contact surface in the pusher plate. Thus, when the penetrator penetrates approximately a body length into the target, the pusher plate is stripped from the penetrator and its effect on further penetration of the penetrator disappears.

As has been mentioned previously, the right-hand side and bottom surfaces of the target are assigned nonreflecting surfaces. The left-hand side and top surfaces are assigned contact surfaces with the outside surface of the penetrator. The contact surface algorithm in PRONTO 2D [3] code allows the Coulomb sliding interface friction representation with either a constant or a velocity dependent (Equation (1)) coeffcient of friction between contacting surfaces. By varying the coefficient of friction between the penetrator and target surfaces, it is intended to parametrically examine its effect on penetration. Altogether, six different cases have been considered. The first three cases utilize constant coefficients of friction with values of $0.08,0.05$, and 0.0 , respectively. Cases four, five, and six are represented by velocity dependent coefficients of friction. The constant $\gamma$ and $\mu_{0}$ in Equation 1 are taken to be 0.2 and 0.5 , respectively, for all three cases. In Equation 1, the value of $\mu_{\infty}$ is varied from 0.08 , 0.05 , and 0.0 , respectively, for cases four, five, and six. The velocity dependence of these friction coefficients is shown in Figure 3 . The trend of these curves agrees with those measured by Montgomery [7] for gliding metal rotating bands. Also, from the 
studies in [1] and [2], the values of the friction coefficients selected here appear to be within reasonable ranges.

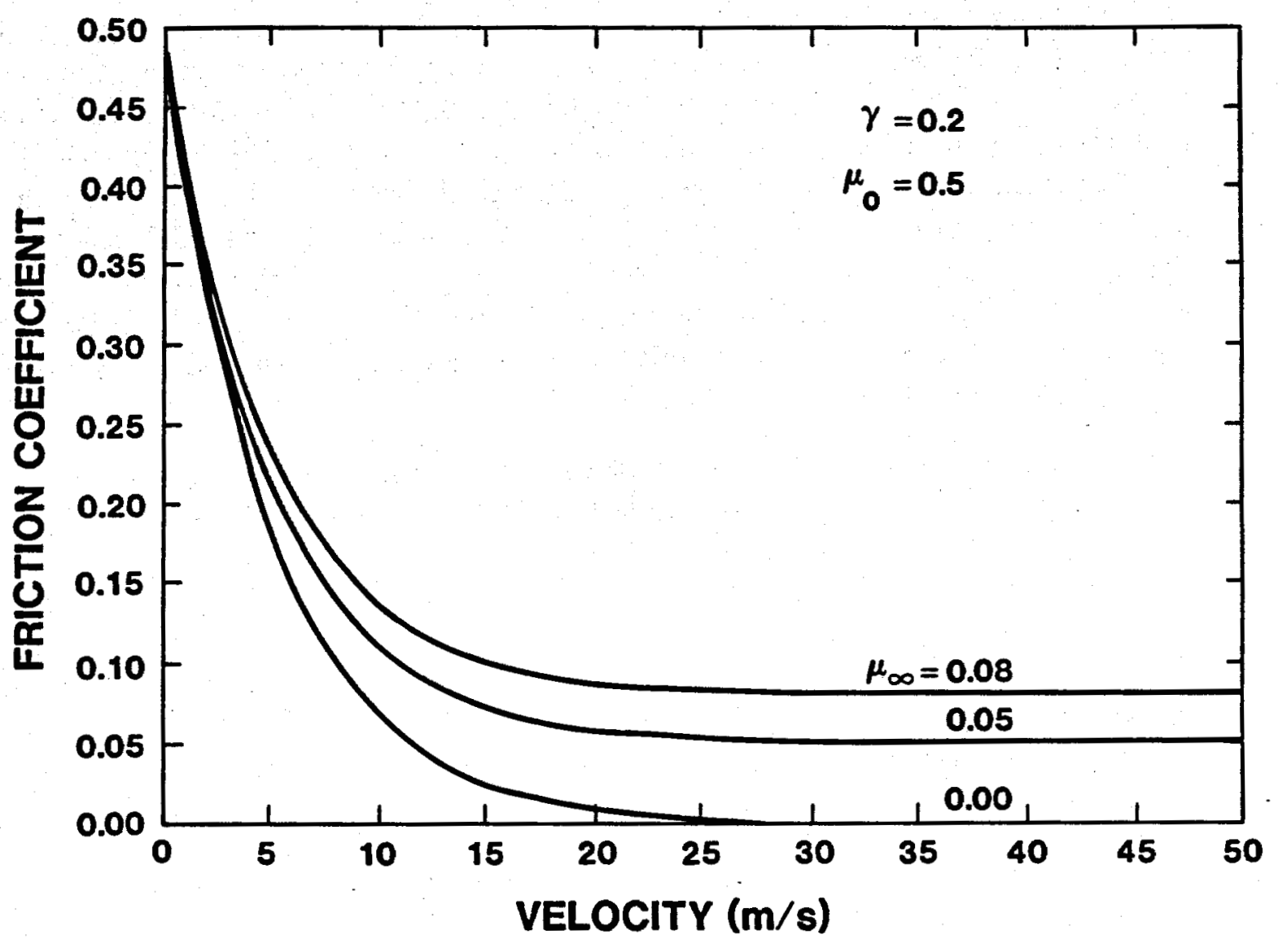

Figure 3. Velocity Dependent Friction Coefficients 


\section{Results and Discussions}

Before proceeding to the presentation of results, the experimentally measured penetrator deceleration history is given in Figure 4 for reference purposes. The

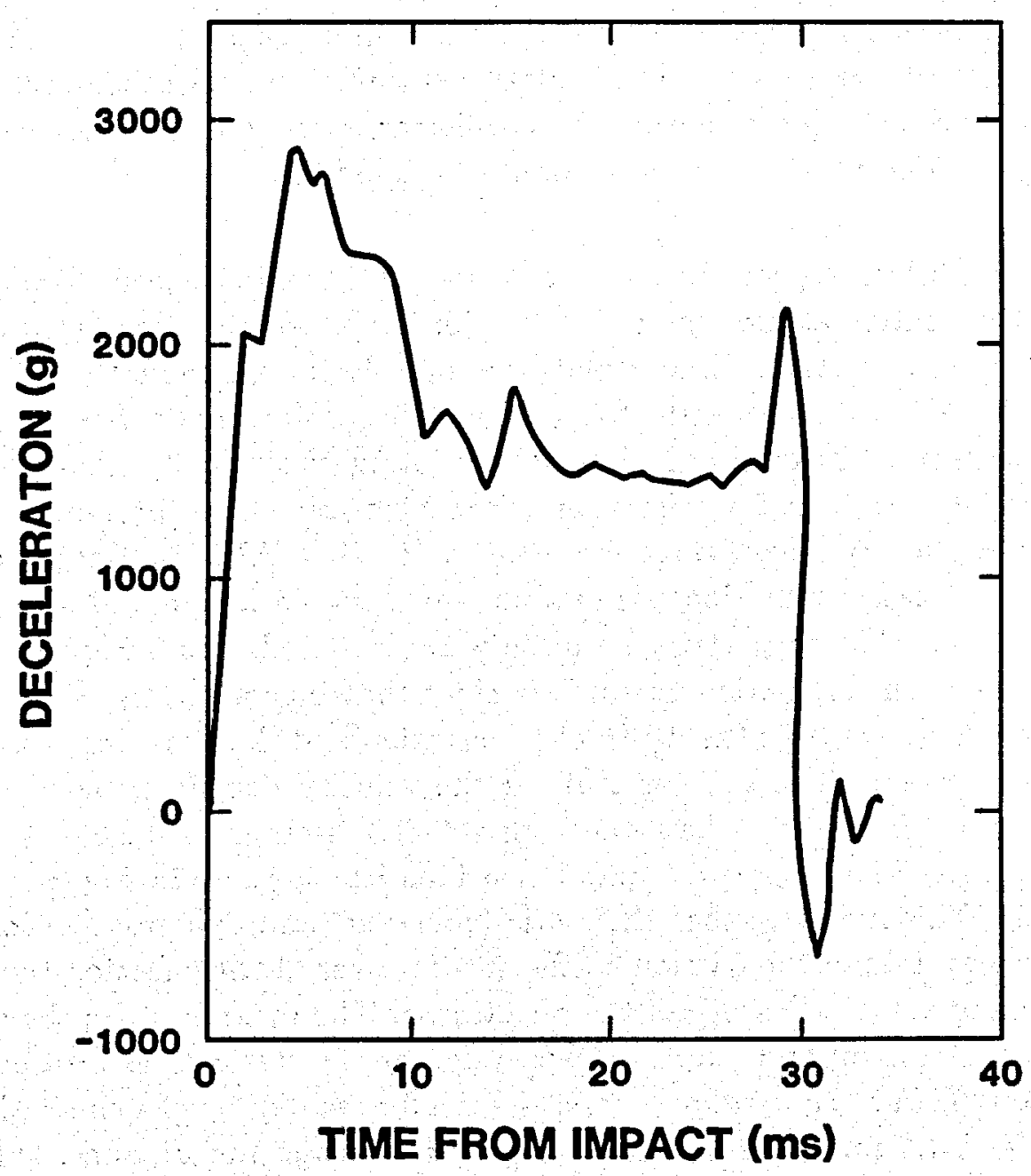

Figure 4. Experimental Data on Deceleration History

measured depth of penetration was $7.0 \mathrm{~m}$. It must be emphasized that the purpose of present study is to establish the behavior trend of the sliding friction and is not 
to find the best friction fit to the experimental data. As has been stated in the last section, six cases have been treated. The deformed mesh history plots for case 3 in which the sliding coefficient is taken to be a constant with $\mu=0.0$ are shown in Figures 5 and 6, respectively, for early and later times. The severe distorsion of the target around the penetrator is evident in these figures. The stripping of the pusher plate is also shown in Figure 5. Because of the bulging of the target at the top surface, penetration of the pusher plate into the target occurs. This pusher plate-target material interaction will only influence the deformation patterns of the pusher plate and of the local areas in the target near the center and on the top surface. It is not expected to have any significant effect on the penetration process of the penetrator. Figure 6 also shows that the penetrator rebounds after its downward motion terminates. These plots are typical for all other cases. The amount of rebounding is dependent on the coefficient of friction; that is, the larger the coefficients of friction, the less the amount of rebounding.

Figures 7-9 exhibit, respectively, the time histories of the downward displacement, velocity, and acceleration at the center of gravity of the penetrator for the three cases of constant coefficient friction. Similar plots for the velocity dependent coefficient of friction cases are shown in Figures 10-12. The acceleration plots represent rigid body responses which are obtained by differentiating the velocity history curves and filtering out the resulting acceleration of the high frequency components. The differentiation and filtering were done using the code GRAFAID [8]. Recall that for velocity dependent cases, Equation 1 is used in which the parameters $\mu_{0}$ and $\gamma$ have been fixed at 0.5 and 0.2 , respectively, and only $\mu_{\infty}$ is varied. From Figures 7-8 for the constant coefficient of friction cases, it is clear that increasing the value of the coefficient of friction decreases the depth of penetration and the time duration of the total penetration event. The same is true for the velocity dependent coefficient of friction cases in Figures 10-11 where the high velocity friction coefficient is varied. In fact the curves in Figures 7 and 8 are almost identical to those in Figures 10 and 11, respectively. This indicates that the static (constant) and dynamic (velocity dependent) representation of the friction coefficient have very little effect on the depth of penetration and velocity history of the penetrator. The maximum depths of penetration are $5.1 \mathrm{~m}, 5.8 \mathrm{~m}$, and $7.5 \mathrm{~m}$, respectively, for the static cases of $\mu$ equal to $0.08,0.05$, and 0.0 . For the dynamic cases, the maximum depths of penetration are $5.2 \mathrm{~m}, 5.8 \mathrm{~m}$, and $7.5 \mathrm{~m}$. Figure 9 shows that by increasing the friction coefficient, the peak value of the deceleration has also been elevated. Typically, the first peak in the deceleration curve corresponds to the time at which the nose of the penetrator is embeded in the target, and the second peak occurs immediately after the time at which the pusher plate has been stripped. Beyond this point in time, the deceleration decreases with time until the arrest of the penetrator when it suddenly drops to zero. The same characteristics are observed in Figure 12 for the dynamic case except 
that immediately before the conclusion of the penetration event, a sudden surge in the deceleration occurs because of the increase in sliding friction as the penetrator velocity decreases to zero. At early times, the deceleration histories for the static and dynamic cases are almost identical to each other. This is evidenced in Figure 13 where the deceleration history curves for the static and dynamic cases with $\mu$ and $\mu_{\infty}$ equal to 0.05 are plotted. However, in reference to Figure 4, the measured data also show the sudden increase in deceleration prior to the arrest of the penetrator. Therefore, the velocity dependent friction coefficient representation appears to be more realistic than the constant representation. In Figure 12, the magnitudes of the peak deceleration immediately prior to the arrest of the penetrator appears to be the same for all three cases. This peak magnitude is dependent on the sliding friction coefficient at low velocities. Since in the present calculations, the low velocity friction coefficient is fixed at $\mathbf{0 . 5}$ for all three cases, the resulting peak decelerations are therefore similar. 

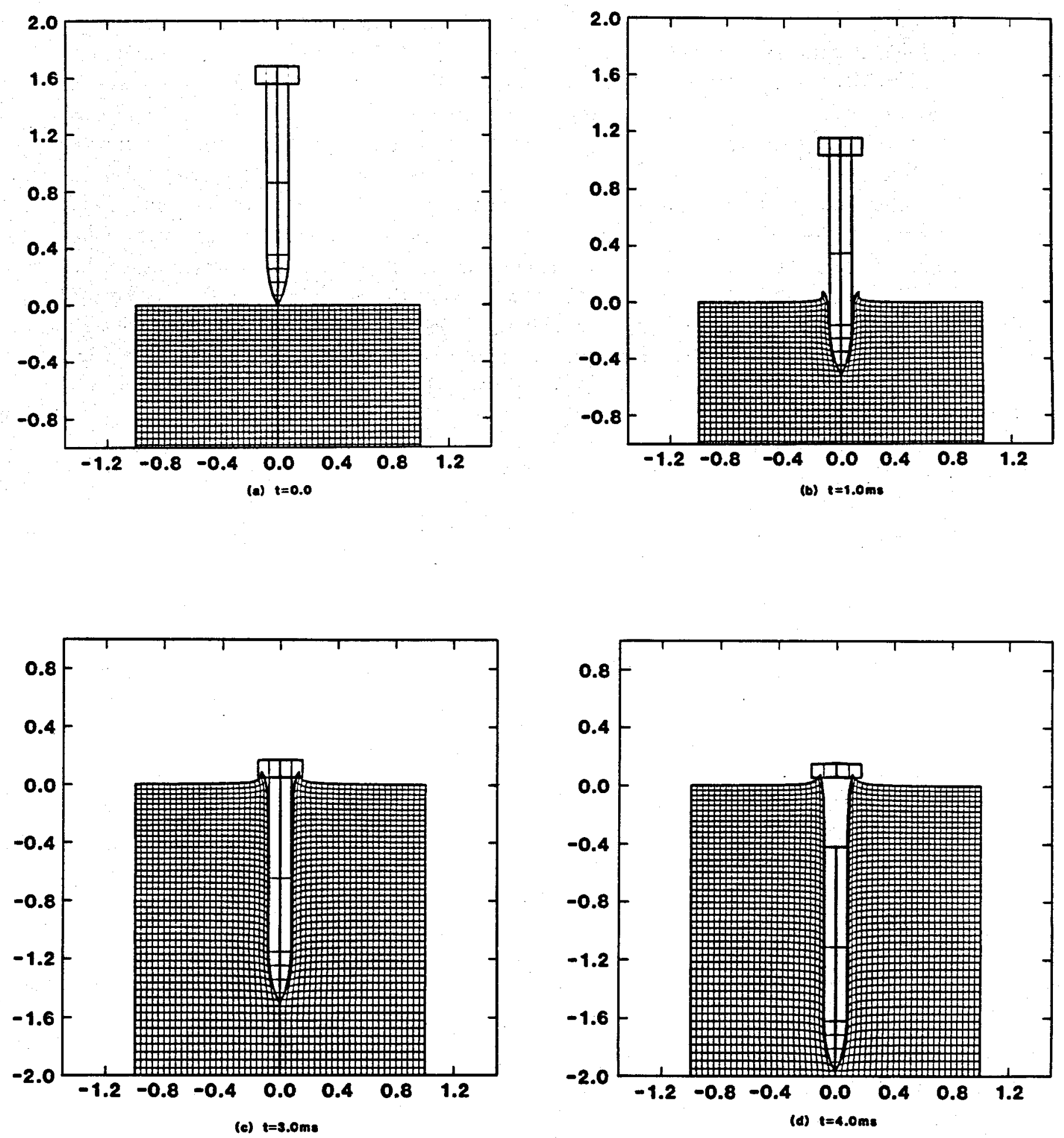

Figure 5. Early Time Deformed Mesh Plots 


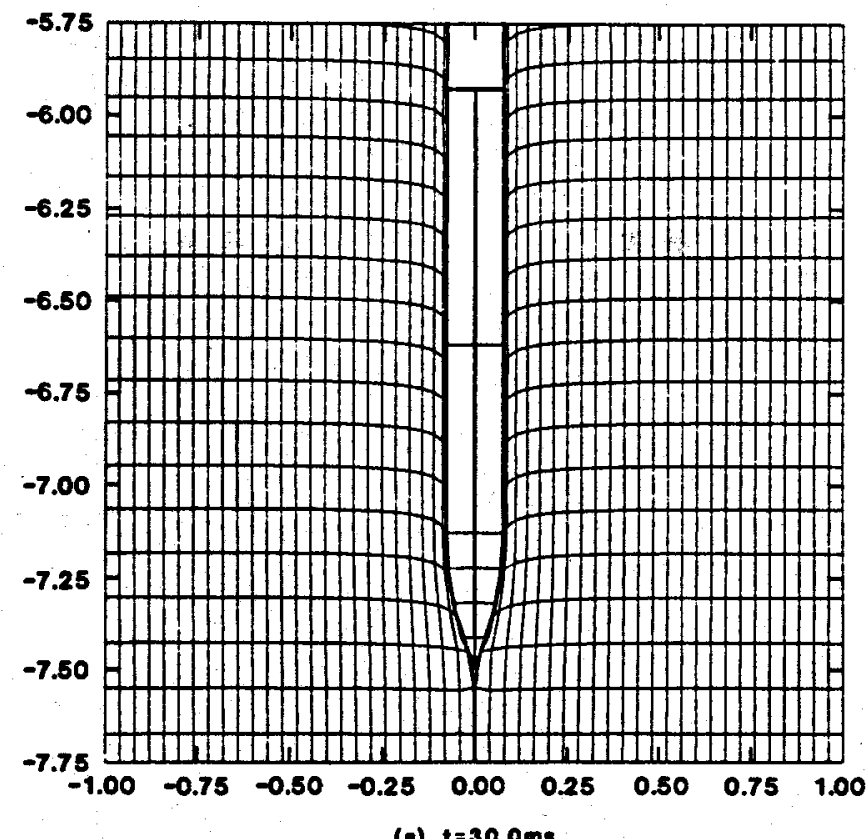

(a) $t=30.0 \mathrm{~ms}$



Figure 6. Late Time Deformed Mesh Plots 


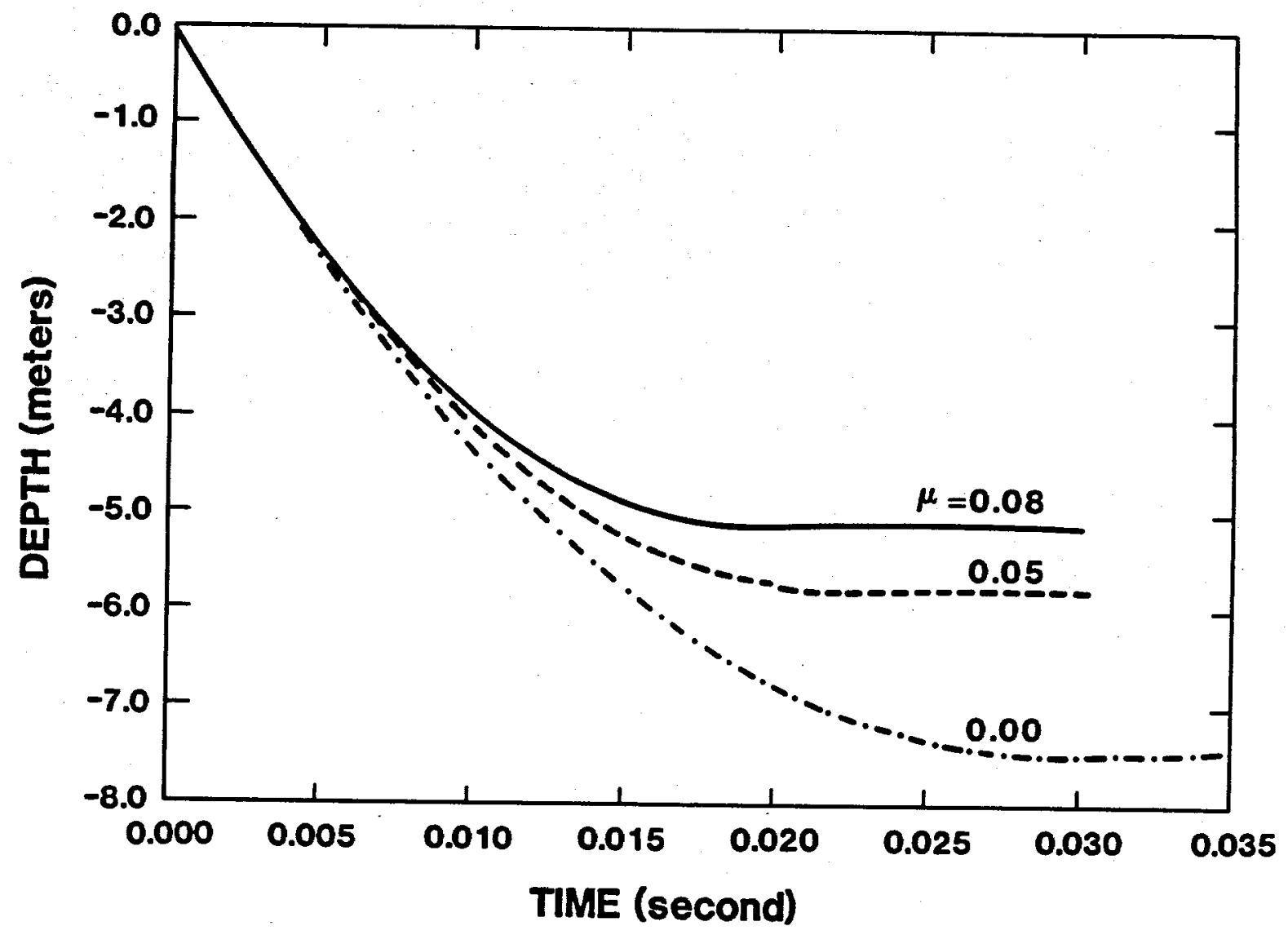

Figure 7. Displacement History Plots for Constant $\mu$ 


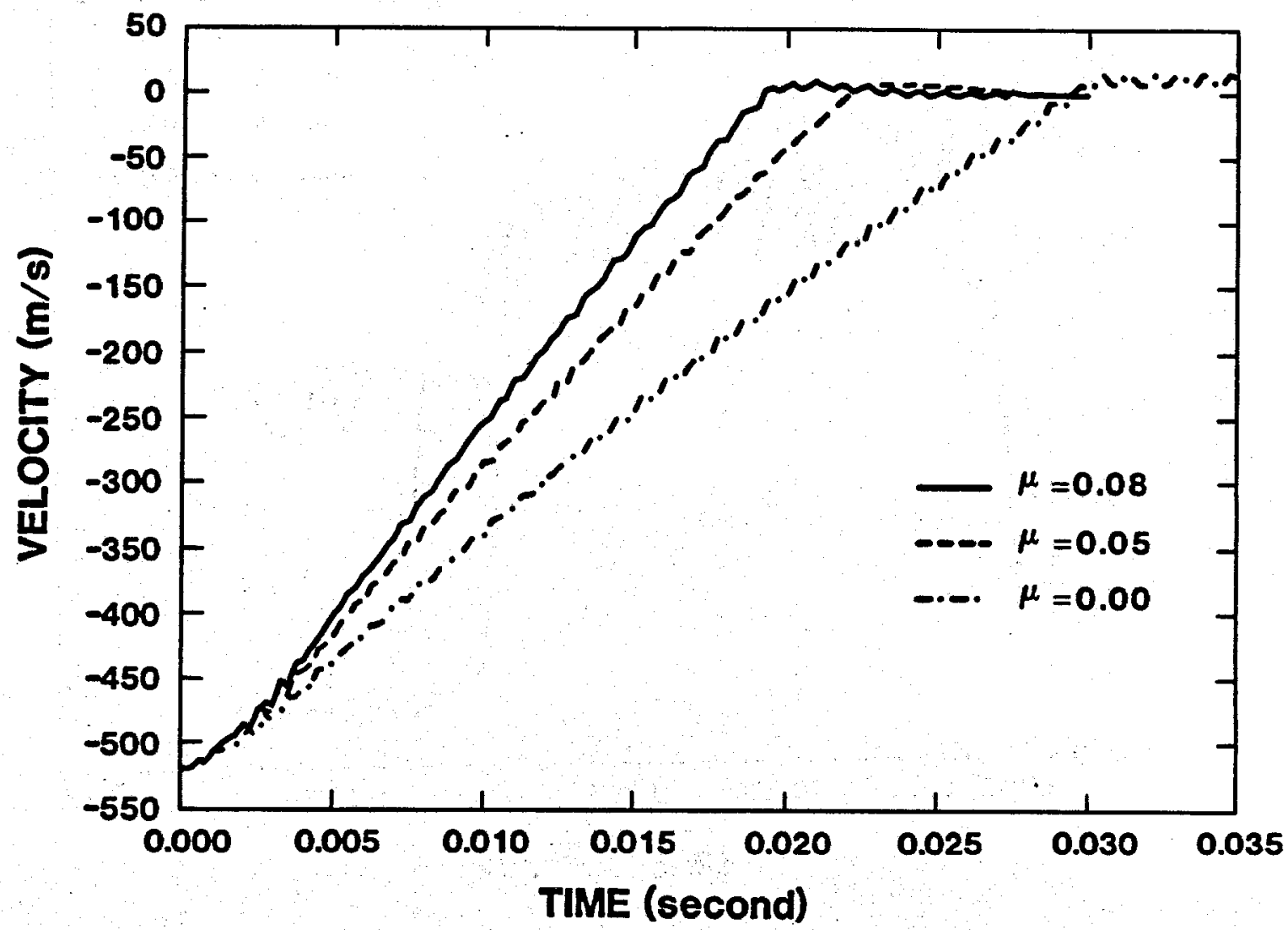

Figure 8. Velocity History Plots for Constant $\mu$ 


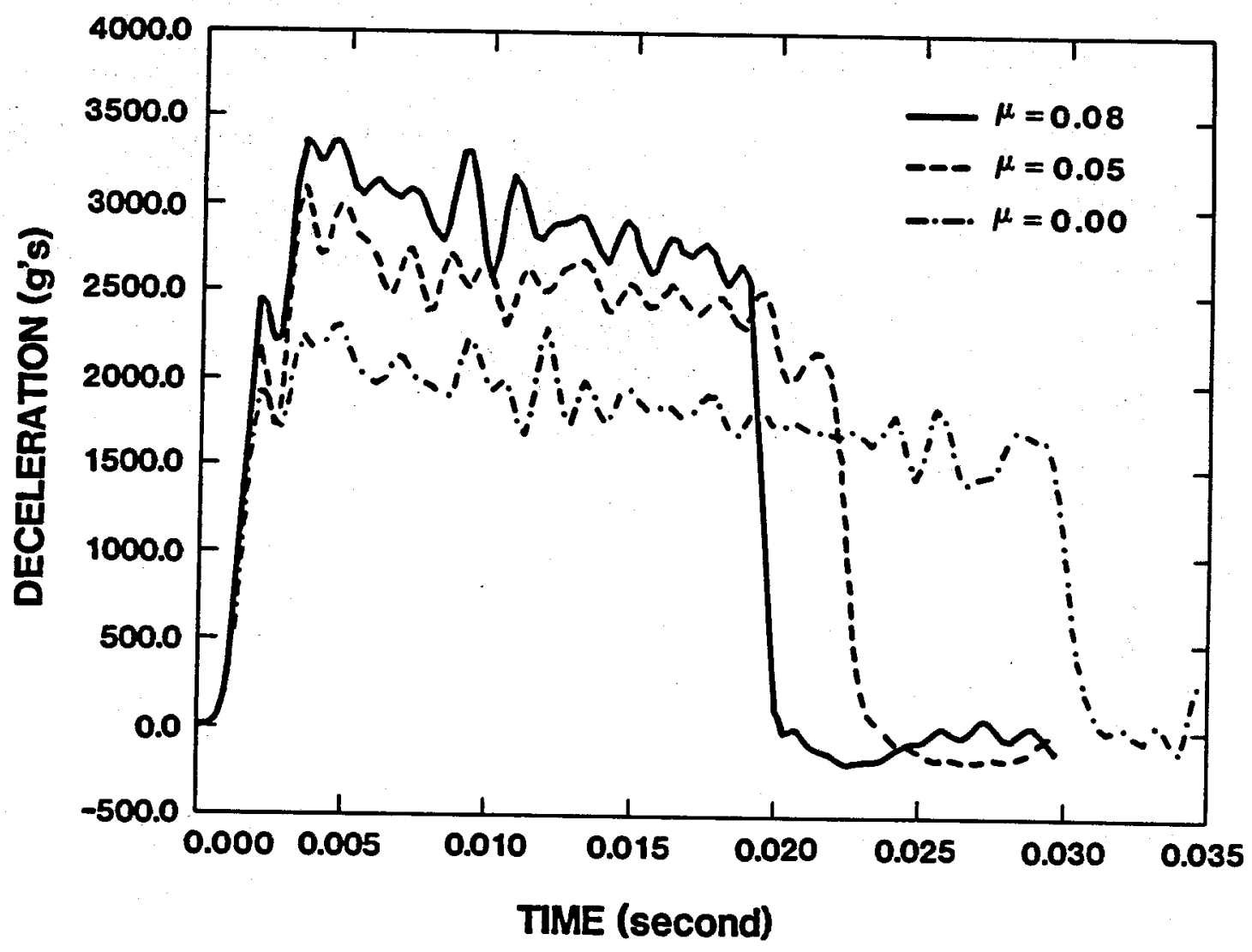

Figure 9. Deceleration History Plots for Constant $\mu$ 


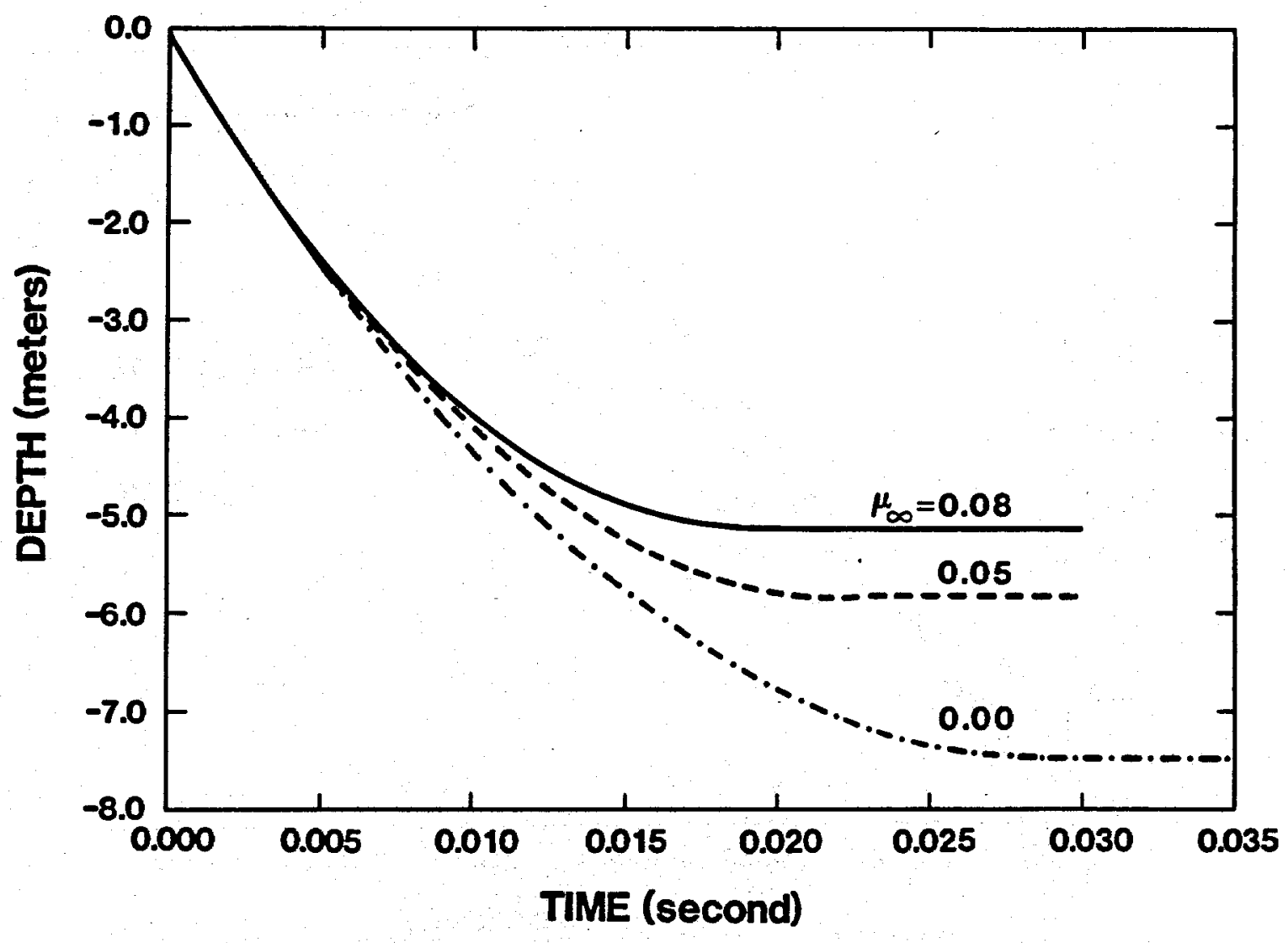

Figure 10. Displacement History Plots for Velocity Dependent $\mu$ 


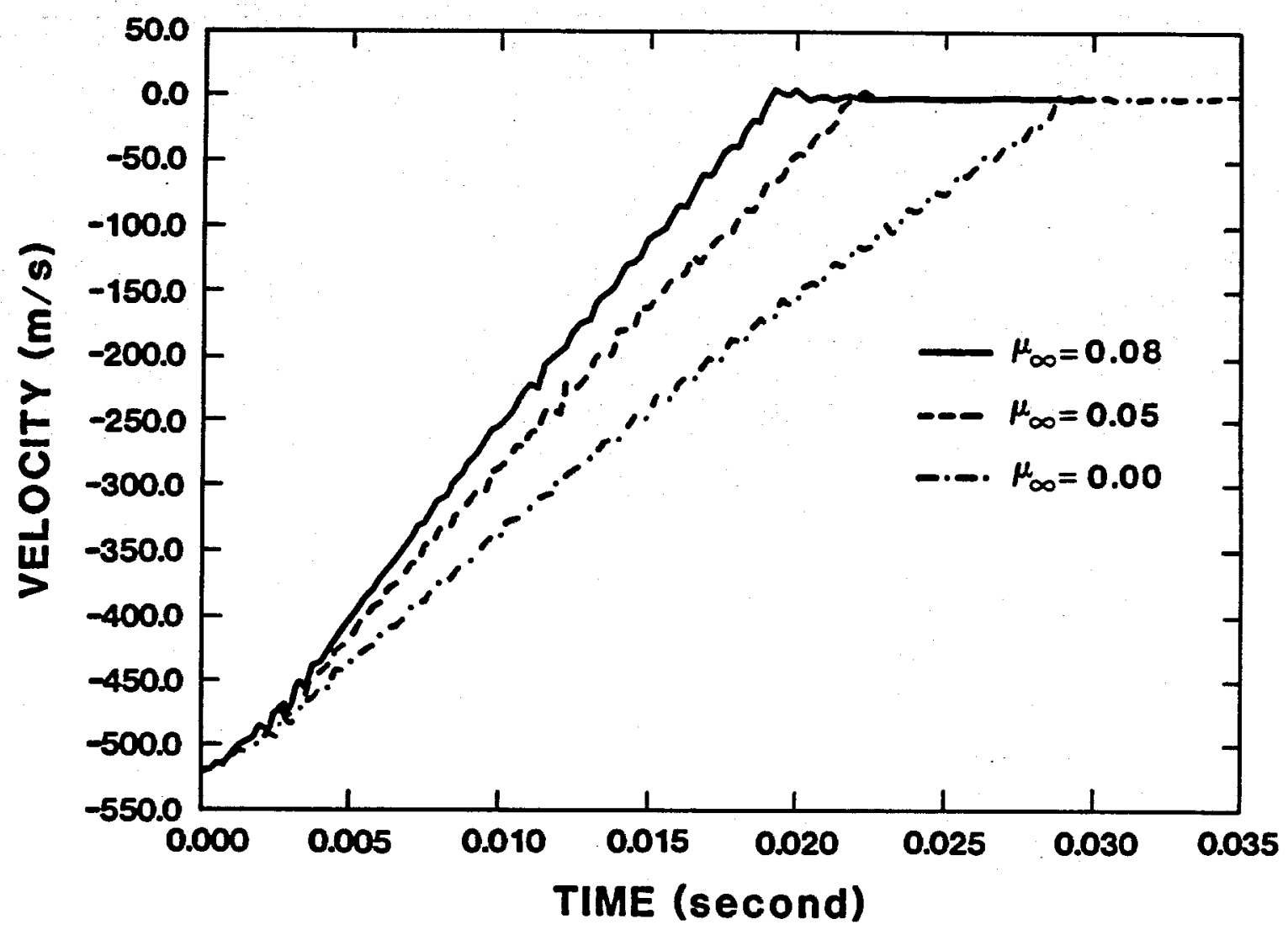

Figure 11. Velocity History Plots for Velocity Dependent $\mu$ 


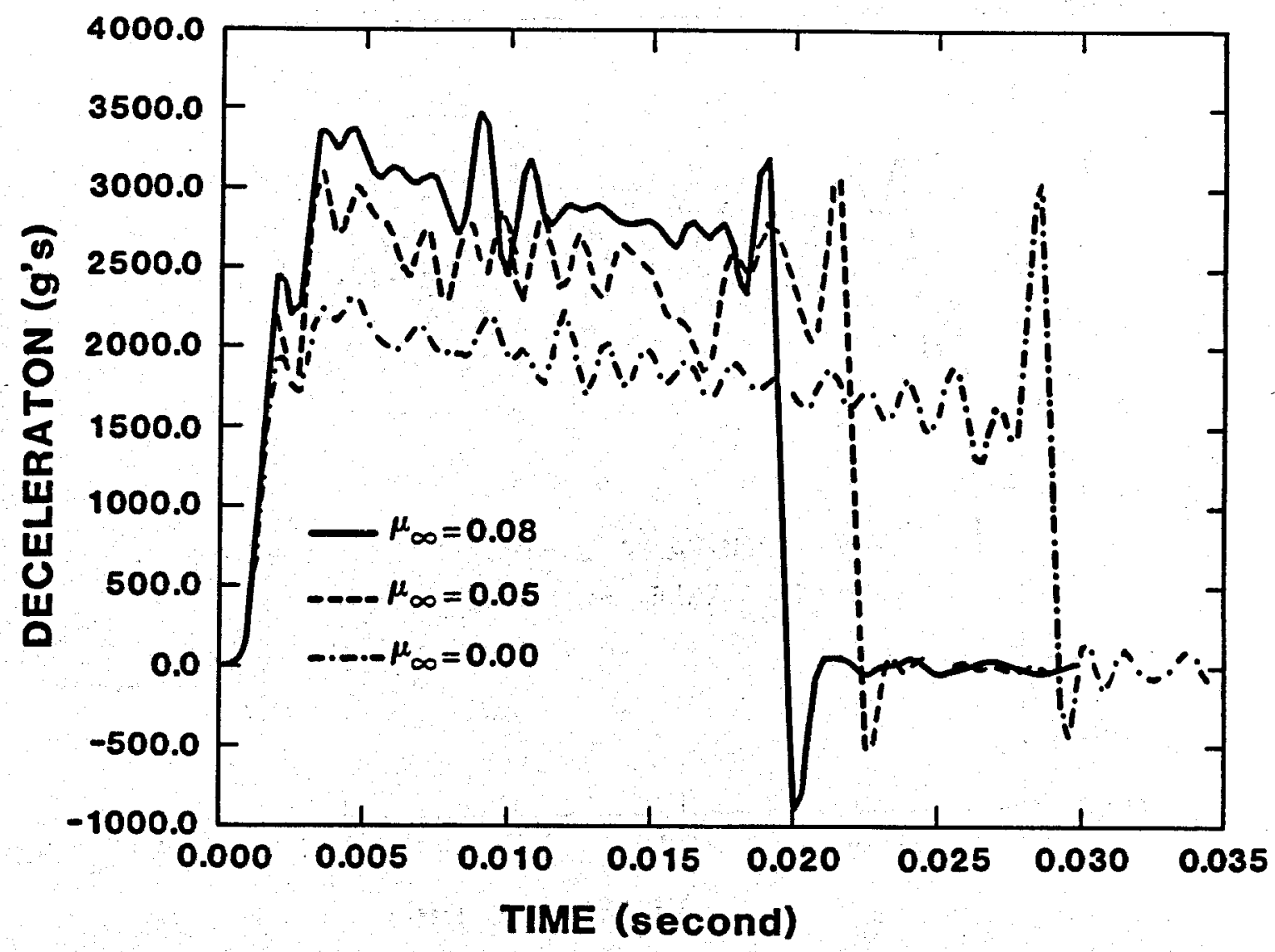

Figure 12. Deceleration History Plots for Velocity Dependent $\mu$ 


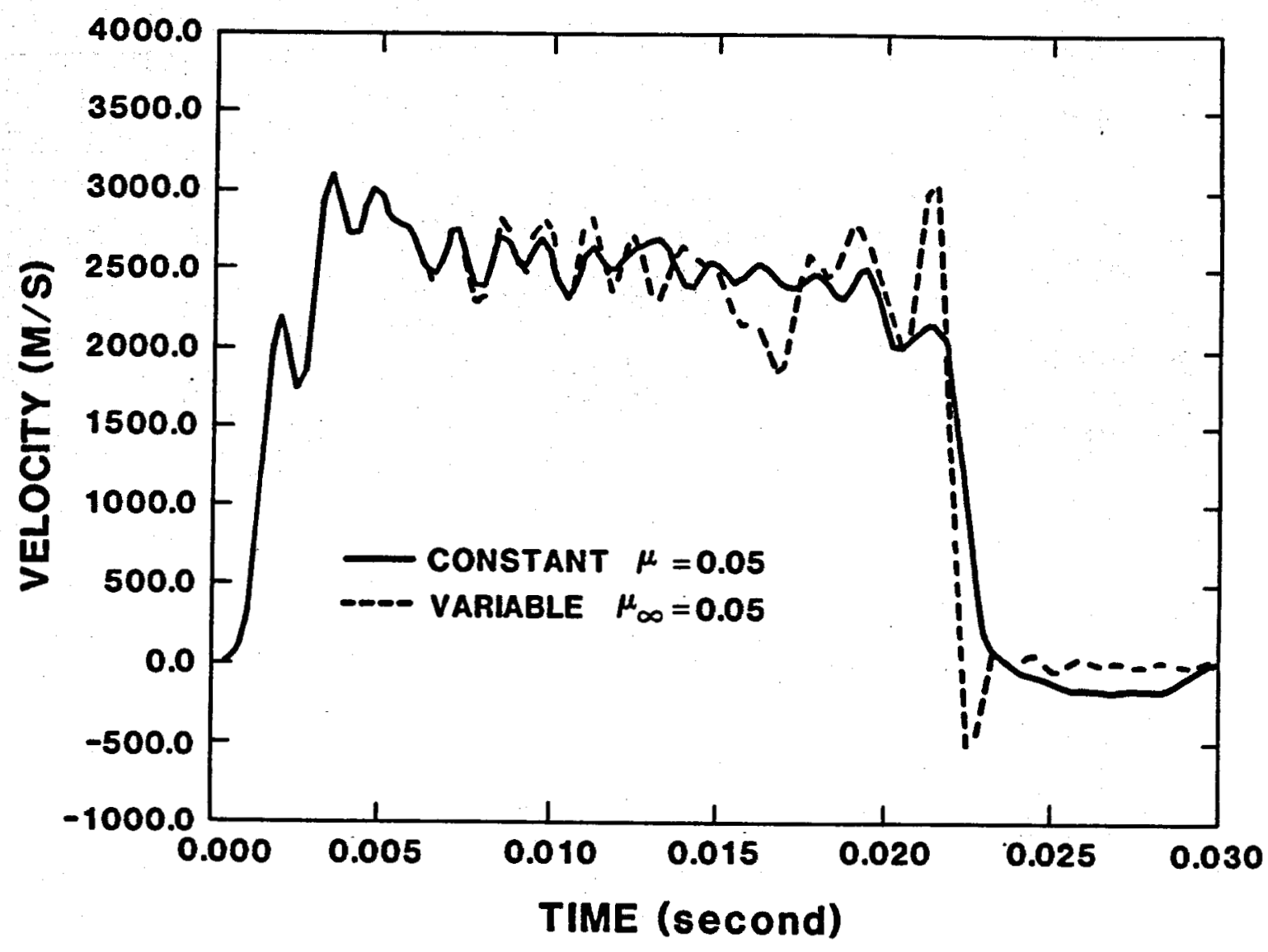

Figure 13. Decelerations for $\mu$ and $\mu_{\infty}$ Equal to 0.05 


\section{Summary}

Finite element analyses of penetration problems into geological media have been performed. Detailed descriptions on material modeling, boundary conditions, and major assumptions are given. Specifically, the effect of sliding friction on penetration was examined. Both the constant and velocity dependent friction coefficient representation have been studied. In terms of the depth of penetration and the peak deceleration, the two representations yield almost identical results. However, because the constant friction coefficient representation cannot model the sudden increase in deceleration prior to the conclusion of the penetration event, the velocity dependent representation should be a preferred model to sliding friction in penetration analysis problems. 


\section{References}

[1] Longcope, D. B. and Forrestal, M. J., Penetration of Targets Described by a Mohr-Coulomb Failure Criterion with a Tension Cutoff, Journal of Applied Mechanics 50, 327-333(1983).

[2] Forrestal, M. J., Penetration into Dry Porous Rock, International Journal of Solids and Structures 22 (12), 1485-1500(1986).

[3] Taylor, L. M., and Flanagan, D. P., PRONTO 2D - A Two-Dimensional Transient Solid Dynamics Program, Sandia National Laboratories Report, SAND860594, Sandia National Laboratories, Albuquerque, NM, 1987.

[4] Young, C. W., Letter Report on Davis Gun Test TP-3 (R801889), Sandia National Laboratories, Albuquerque, NM, 1980.

[5] Chen, E. P., Finite Element Simulation of Penetration Into Geological Targets, Theoretical and Applied Fracture Mechanics 8, 125-135(1987).

[6] Hightower, M. M., Memo to Distribution on Penetration Benchmark Calculation Information, Sandia National Laboratories, Albuquerque, NM, March 16, 1987.

[7] Montgomery, R. S., Surface Melting of Rotating Bands, Wear 38, 235-243(1976).

[8] Adams, C. R., GRAFAID Code User Manual Version 2.0, Sandia National Laboratories Report, SAND84-1725, Sandia National Laboratories, Albuquerque, NM, 1985. 


\section{Distribution:}

Dr. S. C. Chou

SLCMT-BM

U. S. Army Materials and Technology

Laboratory

Watertown, MA 02172-0001

Dr. G. C. Sih

Institute of Fracture and Solid Mechanics

Bldg. 19

Lehigh University

Bethlehem, PA 18015

\section{Sandia Internal:}

1510 J. W. Nunziato

1520 L. W. Davison

1521 R. D. Krieg

1522 R. C. Reuter, Jr.

1522 R. J. Kipp

1522 E. D. Reedy, Jr.

1523 J. H. Biffle

1523 E. P. Chen (10)

1523 D. P. Flanagan

1523 L. M. Taylor

1524 A. K. Miller

1524 D. B. Longcope

1530 D. B. Hayes

1531 L. N. Kmetyk

1533 P. Yarrington

1533 W. T. Brown

1533 G. I. Kerley

1550 C. W. Peterson

3141 S. A. Landenberger (5)

3141-2 For DOE/OSTI (8)

3151 W. I. Klein (3)

5161 J. E. Gronager

5165 W. J. Patterson

5165 R. K. Thomas

8241 M. L. Chiesa

8524 P. W. Dean

9122 M. J. Forrestal

9122 M. M. Hightower

9122 V. K. Luk

9122 C. W. Young 